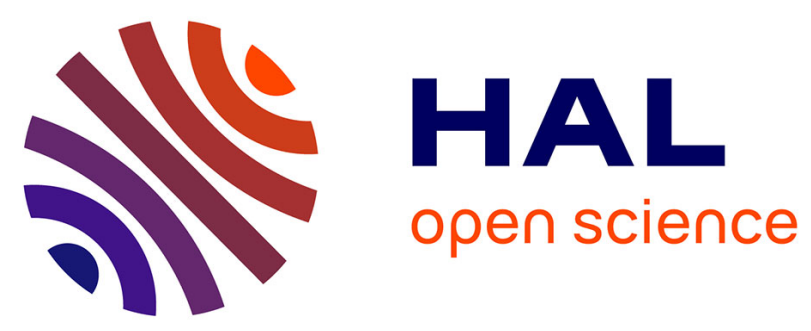

\title{
Application of Arrhenius law to DP and zero-span tensile strength measurements taken on iron gall ink impregnated papers: relevance of artificial ageing protocols
}

Véronique Rouchon, Oulfa Belhadj, Maroussia Duranton, Alice Gimat, Pascale Massiani

\section{To cite this version:}

Véronique Rouchon, Oulfa Belhadj, Maroussia Duranton, Alice Gimat, Pascale Massiani. Application of Arrhenius law to DP and zero-span tensile strength measurements taken on iron gall ink impregnated papers: relevance of artificial ageing protocols. Applied physics. A, Materials science \& processing, 2016, 122 (8), pp.773. 10.1007/s00339-016-0307-1 . hal-01435154

\author{
HAL Id: hal-01435154 \\ https://hal.science/hal-01435154
}

Submitted on 13 Jan 2017

HAL is a multi-disciplinary open access archive for the deposit and dissemination of scientific research documents, whether they are published or not. The documents may come from teaching and research institutions in France or abroad, or from public or private research centers.
L'archive ouverte pluridisciplinaire HAL, est destinée au dépôt et à la diffusion de documents scientifiques de niveau recherche, publiés ou non, émanant des établissements d'enseignement et de recherche français ou étrangers, des laboratoires publics ou privés. 


\title{
Application of Arrhenius law to DP and zero-span tensile strength measurements taken on iron gall ink impregnated papers: relevance of artificial ageing protocols
}

\author{
Véronique Rouchon $^{1} \cdot$ Oulfa Belhadj $^{1} \cdot$ Maroussia Duranton $^{1} \cdot$ Alice Gimat $^{1,2} \cdot$ \\ Pascale Massiani $^{2}$
}

Received: 23 July 2015/Accepted: 24 July 2016/Published online: 30 July 2016

(C) Springer-Verlag Berlin Heidelberg 2016

\begin{abstract}
Iron gall inks (IGI) were largely used for writing until the nineteenth century. Under certain circumstances, they provoke a substantial degradation of their cellulosic support. It was shown in a previous works that combination of oxygen and iron largely impacts cellulose chain break-

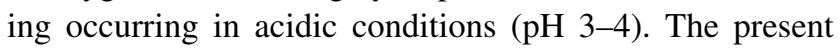
study aims to study the kinetic of this degradation. It assesses the validity of Arrhenius law between 20 and $90{ }^{\circ} \mathrm{C}$ taking advantage of the fast depolymerization of IGI impregnated papers at room temperature and using two complementary tools: DP measurements and zero-span tensile strength. The first one is sensitive enough to measure degradation at its very beginning, while the second is more appropriate for advanced stage of degradation. Similar activation energies $\left(97 \pm 2 \mathrm{~kJ} \mathrm{~mol}^{-1}\right)$ were found via DP and zero-span measurements, and reaction rates of IGI impregnated papers were 1-2 orders of magnitude above available data related to lignin-free acidic papers. These observations suggest a dominant hydrolytic mechanism that involves directly or indirectly oxygen and iron.
\end{abstract}

Véronique Rouchon

rouchon@mnhn.fr

1 Sorbonne Universités, Centre de Recherche sur la Conservation (CRC, USR 3224), Muséum national d'Histoire naturelle, Ministère de la Culture et de la Communication, CNRS, CP21, 36 rue Geoffroy-Saint-Hilaire, 75005 Paris, France

2 Sorbonne Universités, UPMC Univ Paris 06, CNRS UMR 7197, Laboratoire de Réactivité de Surface, 4 place jussieu, 75005 Paris, France

\section{Introduction}

Iron gall inks (IGI) have been extensively used in Western countries for writing and to a lesser extent for drawing. They are made of gall nut extracts rich in gallic acid. When mixed with iron(II) sulphate, these extracts turn instantly towards a dark colour, characteristic of an iron(III)/tannin precipitate. Gum Arabic is added as a binder to create a suspension of the particles that are formed in this manner and thus make the ink more suitable for writing.

IGI have been the scope of many studies [1] because they may, under certain conditions, damage paper, causing browning and loss of mechanical properties such as tensile strength and flexibility. However, the chemistry of these inks still remains poorly understood, mainly because of the high reactivity of iron that allows many interactions with surrounding components: precipitation with gallic acid [2-4], chelation with polysaccharides [5], redox reactions with gallic acid [6], oxidation induced by atmospheric oxygen, etc. All these reactions may compete with each other. Moreover, as most of original recipes correspond to a large excess of iron compared with gallic acid [7], the iron gall ink precipitate formation is most probably not the dominant reaction involving iron.

Paper degradation is usually attributed to the superimposition of acid or alkaline-catalysed hydrolysis and oxidation mechanisms. It inspired many kinetic studies in which depolymerization is quantified by the decline of average number of monomer per macromolecule, also called degree of polymerization, and hereafter referred to as DP. The Ekenstam approach is generally considered in order to model the decrease in $\mathrm{DP}(t)$ versus time at a given temperature [8]:

$1 / \mathrm{DP}(t)-1 / \mathrm{DP}_{0}=k t$ 
where $t$ represents the time, $\mathrm{DP}_{0}$ the initial DP value (at $t=0)$ and $k$ the degradation rate.

This approach was recently refined to model advanced stages of degradation [9], but it remains largely reliable on linear polymers in the early stage of degradation. By measuring the degradation rates at different temperatures, the activation energy of cellulose depolymerization $\left(E_{\mathrm{a}}\right)$ is obtained through the Arrhenius law:

$k(T)=A e^{-E a / R T}$

Thus, most kinetic studies involve activation energy measurements [10]. However, many of them consider ageing temperature above $90{ }^{\circ} \mathrm{C}[11,12]$ or very low $\mathrm{pH}$ values $(\mathrm{pH}<1)[13]$. These extreme conditions may provoke additional degradation mechanisms than those occurring during natural ageing of paper. Lower temperatures in the range $60-100{ }^{\circ} \mathrm{C}$ and milder acidic conditions (pH 3-5) were used by Zou et al. [14] and Begin et al. [15], and in such case, the activation energies were between 103 and $118 \mathrm{~kJ} \mathrm{~mol}^{-1}$ depending on the paper and on the way of ageing (Table 1).

The loss of DP also provokes a loss of mechanical properties, a second aspect in which paper conservators and curators have a major interest. Therefore, Arrhenius plots were additionally drawn with data related to mechanical properties applying mathematical treatments similar to that of Eq. (1), yet replacing (DP) ${ }^{-1}$ by the measured quantity [16] (Eq. 3a) or by the inverse of the measured quantity [17] (Eq. 3b):

$$
\begin{aligned}
& M(t)-M_{0}=k t \\
& 1 / M(t)-1 / M_{0}=-k t
\end{aligned}
$$

In these equations, $M(t)$ stands for the measured quantity and strongly depends on the type of mechanical testing to be considered. There is a priori no strong evidence regarding which of Eqs. (3a) or (3b) is physically the most relevant to model the evolution of $M(t)$. This might explain why a large range of activation energy values was found (between 92 and $165 \mathrm{~kJ} \mathrm{~mol}^{-1}$ ) depending on the chosen papers, mechanical tests and data treatment $[16,17]$.

All these studies find a direct application in the estimation of lifetime expectancies for collection management purposes (see, for instance, recommendations from the Commission on Preservation and Access [18] or from the British Standard Institute [19]). This presupposes extrapolating Arrhenius plots obtained at high temperature (accelerated ageing) to room temperature (natural ageing). These extrapolations, crucial for the reliability of the models, are based on the assumption that no change in the degradation mechanism takes place between low and high temperature. Moreover, since Arrhenius law is exponential, small experimental errors in $E_{\mathrm{a}}$ values at high temperature induce through extrapolation at room temperature huge uncertainties in lifetime expectancies. In addition, paper depolymerization being very slow below $50{ }^{\circ} \mathrm{C}$, few experimental evidence of the extrapolation validity exists, thus questioning the reliability of accelerated ageing protocols. Up to now, the only quantitative comparison of accelerated and natural ageing was drawn by Zou et al. [20] who had access in the $90 \mathrm{~s}$ to paper pulps that were already analysed in the $70 \mathrm{~s}$ and kept meanwhile in relatively constant humidity and temperature conditions. They found a good correlation with the prediction of their kinetic model considering an $E_{\mathrm{a}}$ value of $109 \mathrm{~kJ} \mathrm{~mol}^{-1}$.

From a chemical point of view, a consensus has been reached on the fact that acid-catalysed hydrolysis is the main pathway of acidic paper degradation below $100{ }^{\circ} \mathrm{C}$ $[10,21,22]$ while oxidation prevails over $100^{\circ} \mathrm{C}$. Surprisingly, the great majority of kinetic studies rely on experiments performed in aerated conditions. Also, if a degradation pathway is driven by both oxygen and low $\mathrm{pH}$ values, it would naturally be interpreted as acid-catalysed hydrolyses. It is nevertheless considered that the predominant degradation route in dark at mild environmental conditions is that of hydrolysis and potential oxidation mechanism could play merely a synergistic role. These general considerations largely prevail on iron-free papers, but in case of iron gall ink impregnated papers, the dominant mechanism of degradation remains questionable because (i) there is no exhaustive kinetic study dealing with iron-containing papers and (ii) the rich chemistry of iron may allow alternative pathways.

The acidity of the ink is evidently a damaging factor. It has been shown that the paper nearby the ink line has often a low $\mathrm{pH}$ value [23] which implies acid-catalysed hydrolysis reactions. In addition to that, an oxidative degradation pathway is often suggested in the case of IGI manuscripts. It is related to the presence of iron(II) that promotes highly reactive hydroxyl radicals formation through Fenton reactions [24]. The predominance of this oxidative mechanism was evidenced on deacidified IGI impregnated papers [25] (pH 6.5-8). Its occurrence at lower $\mathrm{pH}$ values was not highlighted and thus remains questionable.

In a previous work, using anoxic and aerated ageing conditions, we showed that the combination of oxygen and iron was a key factor for cellulose chain breaking occurring in acidic conditions ( $\mathrm{pH} 3-4$ ) [26]. Therefore, paper degradation induced by IGI would be predominantly driven by oxidative mechanisms involving iron or cellulose. Nevertheless, additional knowledge on this aspect is still required, and this will be part of the questions raised in the present work.

Another relevant information gained from our abovementioned work [26] lies in the fact that cellulose depolymerization was sufficiently fast to be measured at 
Table 1 Selection of some activation energy values related to paper degradation

\begin{tabular}{|c|c|c|c|c|c|}
\hline Author & Tested material & HR & $\mathrm{T}\left({ }^{\circ} \mathrm{C}\right)$ & $E_{\mathrm{a}}\left(\mathrm{kJ} \mathrm{mol}^{-1}\right)$ & Data considered \\
\hline \multirow[t]{4}{*}{ This work } & \multirow[t]{2}{*}{ Whatman paper impregnated with Fe } & \multirow[t]{2}{*}{$50 \%$} & $23-90$ & $98.6 \pm 2.5$ & DP (Ekenstam) \\
\hline & & & $40-80$ & $96.6 \pm 2.4$ & Zero-span \\
\hline & \multirow[t]{2}{*}{ Whatman paper impregnated with $\mathrm{Fe}+\mathrm{Ac}$} & \multirow[t]{2}{*}{$50 \%$} & $23-90$ & $95.3 \pm 1.7$ & DP (Ekenstam) \\
\hline & & & $23-90$ & $98.3 \pm 3.1$ & Zero-span \\
\hline \multirow[t]{8}{*}{ Daruwalla et al. [13] } & \multirow[t]{2}{*}{ Cotton cellulose in $\mathrm{HCl}, 1 \mathrm{~N}$} & \multirow[t]{2}{*}{$100 \%$} & \multirow[t]{2}{*}{$30-50$} & 95.4 & DP (early stage) \\
\hline & & & & 123.8 & DP (advanced stage) \\
\hline & \multirow[t]{2}{*}{ Regenerated cellulose in $\mathrm{HCl}, 1 \mathrm{~N}$} & \multirow[t]{2}{*}{$100 \%$} & \multirow[t]{2}{*}{$30-50$} & 95.0 & DP (early stage) \\
\hline & & & & 113.8 & DP (advanced stage) \\
\hline & \multirow[t]{2}{*}{ Cotton cellulose in $\mathrm{H}_{2} \mathrm{SO}_{4}, 0.1 \mathrm{~N}$} & \multirow[t]{2}{*}{$100 \%$} & \multirow[t]{2}{*}{$30-50$} & 87.0 & DP (early stage) \\
\hline & & & & 113.8 & DP (advanced stage) \\
\hline & \multirow[t]{2}{*}{ Regenerated cellulose in $\mathrm{HCl}, 1 \mathrm{~N}$} & \multirow[t]{2}{*}{$100 \%$} & \multirow[t]{2}{*}{$30-50$} & 91.2 & DP (early stage) \\
\hline & & & & 114.6 & DP (advanced stage) \\
\hline \multirow[t]{3}{*}{ Zou et al. [14] } & Bleached softwood bisulphite pulp, $\mathrm{pH} 4.8$ & \multirow[t]{3}{*}{$75 \%$} & \multirow[t]{3}{*}{$60-100$} & $104 \pm 3$ & \multirow[t]{3}{*}{ DP (Ekenstam) } \\
\hline & Bleached softwood kraft pulp, $\mathrm{pH} \approx 4$ & & & $111 \pm 4$ & \\
\hline & Bleached softwood kraft pulp, $\mathrm{pH} \approx 4$ & & & $103 \pm 5$ & \\
\hline Zou et al. [20] & Bleached kraft pulps & $50 \%$ & $23^{\circ} \mathrm{C}$ & 109 & DP (Ekenstam) \\
\hline \multirow[t]{4}{*}{ Begin et al. [15] } & \multirow{2}{*}{$\begin{array}{l}100 \% \text { Softwood bleached ChemiThermoMechanical } \\
\text { pulp, pH } 5\end{array}$} & \multirow[t]{4}{*}{$65-72 \%$} & \multirow[t]{4}{*}{$65-90$} & 103 & DP (free sheet) \\
\hline & & & & 114 & DP (Stack) \\
\hline & \multirow[t]{2}{*}{$100 \%$ Bleached northern softwood kraft pulp, pH 5} & & & 106 & DP (free sheet) \\
\hline & & & & 118 & DP (stack) \\
\hline \multirow[t]{2}{*}{ Shahani et al. [16] } & \multirow{2}{*}{$\begin{array}{l}\text { Paper, } 100 \% \text { bleached northern softwood kraft paper, } \\
\text { alum sized, pH 5.7, aged in glass tubes }\end{array}$} & \multirow[t]{2}{*}{$56-60 \%$} & $70-90$ & 113 & Zero-span \\
\hline & & & & 108 & $\mathrm{DP}$ \\
\hline Rychly et al. [35] & Whatman paper & $0 \%$ & $40-220$ & 83.7 & CI (early stage) \\
\hline Kocar et al. [21] & Paper, bleached sulphate softwood pulp, no size & $0 \%$ & $60-220$ & $93 \pm 2$ & DP (Ekenstam) \\
\hline & & $65 \%$ & $60-90$ & $126 \pm 12$ & DP (Ekenstam) \\
\hline Shafizadeh et al. [11] & Cotton cellulose linters, ageing in air & $0 \%$ & $150-190$ & 88 & DP (Ekenstam) \\
\hline & Cotton cellulose linters, ageing under nitrogen & $0 \%$ & $150-190$ & 113 & DP (Ekenstam) \\
\hline & & & & 110 & CI (advanced stage) \\
\hline Kwon et al. [43] & Cellobiose in $\mathrm{H}_{2} \mathrm{SO}_{4}$ solution & Solution & $25-80$ & $110 \pm 7$ & Glucose formation \\
\hline & & & & $118 \pm 8$ & Cellobiose hydrolysis \\
\hline & Cellobiose in a Fenton reaction system & Solution & $25-80$ & $55 \pm 1$ & Glucose formation \\
\hline
\end{tabular}

This selection focusses on ageing conditions relatively close to those used in this study and/or on data that are found relevant to the discussion. $C I$ Chemiluminescence intensity

room temperature. This point is quite unusual as most kinetic studies on paper degradation involve artificial ageing protocols using relatively high temperatures [10].

Based on this previous knowledge, the present study aims to evaluate the relevance of Arrhenius law extrapolations taking advantage of the fast depolymerization of IGI impregnated papers (measurable at room temperature) and using two complementary tools: DP measurements and zero-span tensile strength. The first one is sensitive enough to measure degradation at its very beginning, while the second is more appropriate for advanced stage of degradation.

\section{Experimental section}

\subsection{Sample preparation}

Pure laboratory products were used: monohydrate gallic acid (398225, Aldrich) and heptahydrate iron(II) sulphate (215422, Aldrich). Three model ink solutions were prepared with different concentrations of these products, chosen according to criteria already largely described in a previous work [26]. All solutions were stirred for 3 days in closed vessels, and then, paper sheets (Whatman No 1, $10 \mathrm{~cm}$ large square) were immersed for $10 \mathrm{~min}$. After- 
wards, the sheets were placed between two Cobb blotting papers [27], and the excess of ink was mopped up by using a $10-\mathrm{kg}$ Cobb roll back and forth. This procedure allows an even deposition of the solution, with a lateral dispersion of $\pm 5 \%$. The concentration of iron deposited on the samples, determined by atomic absorption spectroscopy [28], is close to $0.8 \%$ w/w for both $\mathrm{Fe}$ and $\mathrm{Fe}+$ Ac paper sheets. After impregnation, the papers were dried overnight for $17 \mathrm{~h}$ at $23{ }^{\circ} \mathrm{C}$. The sample names and concentrations of solutions used for their impregnation are given in Table 2 with $\mathrm{pH}$ measurements of cold paper extracts according to standard protocol [29].

Ageing at ambient temperature was performed in a small glove box placed in an air-conditioned room $\left(23^{\circ} \mathrm{C}\right)$ and buffered at $50 \% \mathrm{RH}$ with silica gel (PROSorb, Long Life for Art, Germany) pre-conditioned in a climatic chamber at $50 \%$ RH. For artificial ageing at higher temperature, samples were cut in smaller pieces (avoiding edges) and placed in closed vessels with an experimental set-up described elsewhere [30] yet using silica gel (PROSorb, Long Life for Art, Germany; pre-conditioned at $50 \% \mathrm{RH}$ ) instead of paper for humidity buffering. Humidity was monitored during ageing $(50 \pm 5 \% \mathrm{RH})$ by small sensors placed in the vessel (Hygrobutton, ProgesPlus, USA). In order to avoid temperature and humidity fluctuation during sample transfer, each vessel was filled with one sample only, meaning that there were as many samples as measurements $(\sim 85,12$ and 60 samples for $\mathrm{Fe}+\mathrm{Ac}, \mathrm{Fe}+\mathrm{Ac}$ conc and Fe solutions, respectively).

\subsection{Degree of polymerization}

The degree of polymerization (DP) was determined by standard viscosity measurements using cupriethylenediamine (CED) as solvent [31]. The limiting viscosity number $[\eta]$ was measured 10-15 min after paper dissolution. In order to evaluate possible artefacts due to cellulose-oxidized groups, preliminary tests were performed implementing a sodium borohydride reducing treatment prior CED dissolution. Similar values of $[\eta]$ were obtained compared with

Table 2 Sample preparation

\begin{tabular}{lllll}
\hline $\begin{array}{l}\text { Name of paper } \\
\text { samples }\end{array}$ & $\begin{array}{l}\text { Composition of solution used for } \\
\text { impregnation }\left(\mathrm{g} \mathrm{L}^{-1}\right)\end{array}$ & $\begin{array}{l}\text { ink } \\
\mathrm{pH}\end{array}$ & $\begin{array}{l}\text { paper } \\
\mathrm{pH}\end{array}$ \\
\cline { 2 - 3 } & $\begin{array}{l}\text { Gallic acid } \\
\text { monohydrate }\end{array}$ & $\begin{array}{l}\text { Iron(II) sulphate } \\
\text { heptahydrate }\end{array}$ & & \\
\hline $\mathrm{Fe}$ & - & 4 & 3.6 & 4.2 \\
$\mathrm{Fe}+\mathrm{Ac}$ & 0.9 & 4 & 3.2 & 3.7 \\
$\mathrm{Fe}+\mathrm{Ac}$ conc & 9 & 40 & 2.6 & 3.2 \\
\hline
\end{tabular}

Composition and $\mathrm{pH}$ of solutions used for impregnation; the $\mathrm{pH}$ of paper was measured on cold extracts [29] after drying at $23{ }^{\circ} \mathrm{C}$ and $50 \% \mathrm{RH}$ for $17 \mathrm{~h}$ those without reducing treatment. The viscosity measurements were therefore taken without reducing treatment.

An accurate determination of the amount of dry cellulose solubilized in CED was achieved by the use of a temperature- and humidity-controlled microbalance equipped with a heating resistance (DVS Advantage, SMS Ltd, UK) that offers the possibility to heat the sample at $120{ }^{\circ} \mathrm{C}$ in order to remove residual water and thus estimate the amount of dry matter.

The limiting viscosity number $[\eta]$ was converted to DP values (i.e. the average number of monomers per macromolecule) using the Mark-Houwink-Sakurada equation:

$[\eta]=K \cdot\left(D P_{v}\right)^{\alpha}$

In Eq. (4), $K$ and $\alpha$ are two constants given for a polymer/solvent system and $\mathrm{DP}_{\mathrm{v}}$ stands for an approximation of the average number of monomers per macromolecule, as measured by viscosimetry.

The values $K=0.91$ and $\alpha=0.85$ were chosen in this study. They were initially proposed by Evan et al. [32] and have largely been used in the cellulose chemistry community for the cellulose/CED system. They lead to $\mathrm{DP}_{\mathrm{v}}$ values that are (i) experimentally consistent with $M_{\mathrm{w}}$ values determined by size exclusion chromatography and (ii) proportional to average number of monomer per macromolecule (DP) with a proportionality factor that is relatively close to 1 [33]. Eq. (2) shows that two proportional quantities will lead to similar activation energy values. Therefore, $\mathrm{DP}_{\mathrm{v}}$, as determined with Eq. (4), appears appropriate for the determination of activation energy values of chain scission and will be hereafter more simply referred to as DP.

\subsection{Mechanical properties}

Loss of mechanical properties was evaluated with a zerospan tensile tester [34] (Pulmac, TS-100) on dried papers, pre-conditioned at $23{ }^{\circ} \mathrm{C}$ and $50 \%$ of relative humidity (RH). This test consists in measuring the failure load necessary to break a strip of paper maintained by two joint clamps. The load, also called zero-span tensile strength, is expressed in $\mathrm{kg}$ per $15 \mathrm{~mm}$. For each sample, 10 measurements were taken and the average was considered. Standard deviation was ranging from $2 \%$ up to $6 \%$.

\section{Results}

\subsection{Determining the amount of dry cellulose for DP measurements}

DP measurements largely rely on an accurate determination of the amount of solubilized cellulose. It appeared useless to weight samples before ink impregnation to 


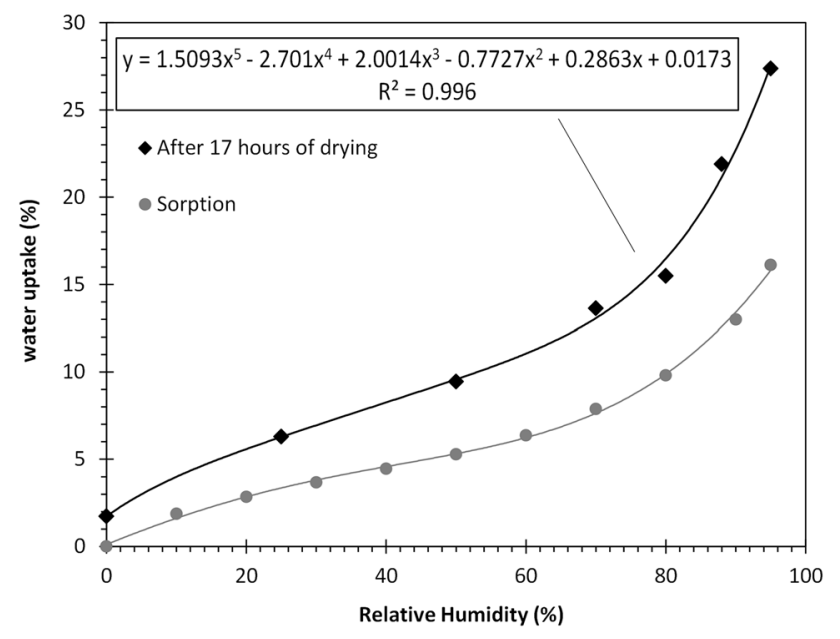

Fig. 1 Water uptake versus humidity at $23{ }^{\circ} \mathrm{C}$. Filled circle sorption isotherm starting with a paper that was previously heated at $120^{\circ} \mathrm{C}$ for $15 \mathrm{~min}$; filled diamond desorption isotherm corresponding to a paper that was immersed for 10 min in water, pressed between two Cobb paper and then exposed for $17 \mathrm{~h}$ to specific values of relative humidity; (-) polynomial fit. All measurements were taken on approximately $10 \mathrm{mg}$ of pure Whatman paper

estimate the amount of dry cellulose because paper edges appeared darker and relatively heterogeneous and had therefore to be taken apart. Samples were also cut out of the central part of the sheets that had a homogeneous aspect. Moreover, when paper is immersed in water and then dried overnight at ambient temperature, a large hysteresis effect is expected, meaning that a sorption isotherm (Fig. 1, grey data) between 0 and $95 \% \mathrm{RH}$ is not appropriate.

Dry cellulose weights were also estimated by the use of the microbalance mentioned above, considering $10 \mathrm{mg}$ of Whatman samples impregnated with pure water and then exposed to fixed humidity conditions. After impregnation, paper retains water to a ratio of approximately $115 \%$ of its own weight. When it is afterwards exposed to air, the water uptake rapidly decreases. The microbalance monitored this weight decrease versus time until equilibrium is reached at requested conditions. It was always observed that an exposure for $17 \mathrm{~h}$ was largely long enough to reach equilibrium. Afterwards, the sample was heated at $120{ }^{\circ} \mathrm{C}$ in order to remove residual water, leading to the determination of dry cellulose weight and water uptake. Several humidity conditions ranging from $0 \% \mathrm{RH}$ up to $97 \% \mathrm{RH}$ were tested this way, and measurements were interpolated (Fig. 1, diamond-shaped data). The BrunauerEmmett-Teller (BET) model was not considered here because it is mainly valid for low moistures (below $40 \% \mathrm{RH}$ ) and does not allow fitting in the whole range of humidity values. A fifthorder polynomial interpolation was preferred although it has no physical meaning.

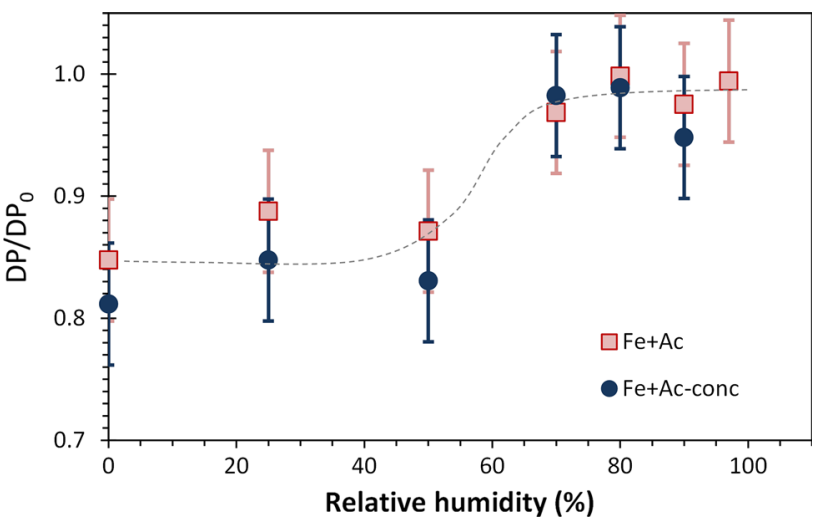

Fig. 2 Retention of DP after $17 \mathrm{~h}$ of drying at $23{ }^{\circ} \mathrm{C}$ and different humidity conditions. Filled square samples $\mathrm{Fe}+\mathrm{Ac}$; filled circle samples $\mathrm{Fe}+\mathrm{Ac}$ conc (see Table 2)

\subsection{Measuring initial degree of polymerization $\left(\mathrm{DP}_{\mathbf{0}}\right)$}

The DP of blank Whatman paper is close to 3100 . Preliminary measurements (not detailed) taken on IGI impregnated papers showed that this value was not stable during drying, which may bring errors in the kinetics measurements. Therefore, the change in DP was also measured in drying conditions with fixed humidity conditions in the range from 0 to $97 \% \mathrm{RH}$ and considering the above-mentioned desorption curve (Fig. 1). A significant DP loss (10-20\%) was observed for the driest conditions $(0-50 \% \mathrm{RH})$, whereas DP remained unchanged for the highest humidity conditions (70-97\% RH) (Fig. 2). Moreover, this phenomenon was more pronounced on the concentrated samples ( $\mathrm{Fe}+\mathrm{Ac}$ conc). In order to avoid confusion on $\mathrm{DP}_{0}$ values in the Ekenstam model, we decided to let dry all IGI papers at $50 \% \mathrm{RH}$ and chose a starting point $(t=0)$ corresponding to $17 \mathrm{~h}$ after impregnation for all artificial ageing experiments.

\subsection{Kinetic approach of chain breaking}

Artificial ageing of IGI impregnated papers was performed at increasing temperatures from 23 to $90{ }^{\circ} \mathrm{C}$. The evolution of DP values was monitored to plot $1 / \mathrm{DP}(t)-1 / \mathrm{DP}_{0}$ versus time (Fig. 3). These curves were linearly interpolated without imposing a fixed value for the origin. The resulting $k(T)$ slopes values were then reported in an Arrhenius plot (Fig. 4), leading to the determination of the following activation energies: $E_{\mathrm{a}}=95.3 \pm 1.7 \mathrm{~kJ} \mathrm{~mol}^{-1}$ for the $\mathrm{Fe}+$ Ac sample and $E_{\mathrm{a}}=98.6 \pm 2.5 \mathrm{~kJ} \mathrm{~mol}^{-1}$ for the $\mathrm{Fe}$ sample. These two values are similar within experimental uncertainties. 
Fig. 3 Ekenstam plots at temperature of ageing ranging $23-90{ }^{\circ} \mathrm{C} .23{ }^{\circ} \mathrm{C}$ (plus symbol); square); $90{ }^{\circ} \mathrm{C}$ (filled circle); Ageing was performed at $50 \%$ $\mathrm{RH}$ $41{ }^{\circ} \mathrm{C}$ (times symbol); $70{ }^{\circ} \mathrm{C}$ (filled triangle); $80{ }^{\circ} \mathrm{C}$ (filled
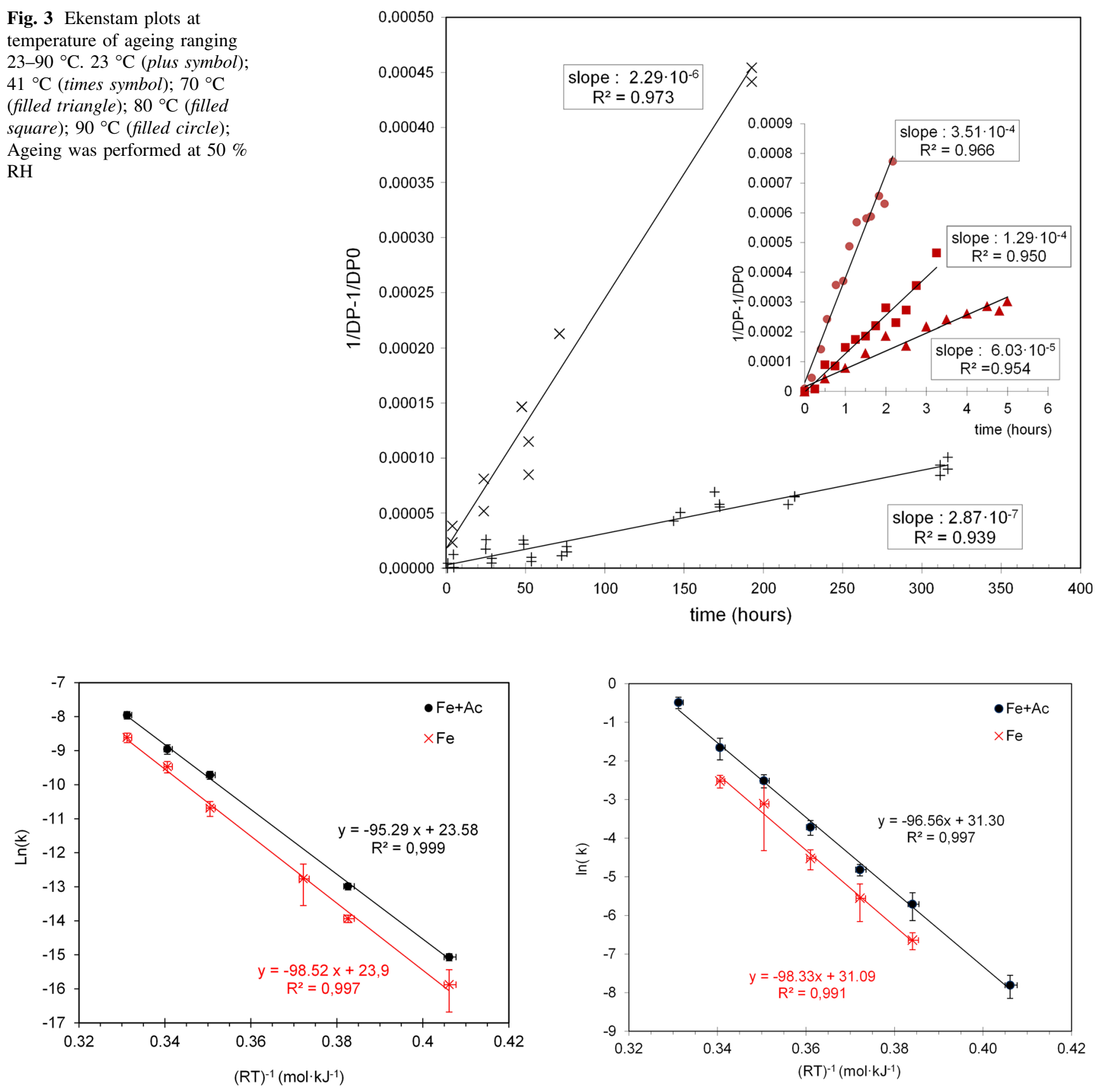

Fig. 4 Arrhenius plot of DP measurements. Samples Fe + Ac (black filled circle); samples Fe (red times symbol)

\subsection{Kinetic approach of mechanical decay}

The evolution of zero-span tensile strength $\mathrm{Z}(\mathrm{t})$ was monitored during ageing on samples that were similar to those used for viscosity measurements, yet aged for longer ageing periods $\left(3000 \mathrm{~h}\right.$ at $23{ }^{\circ} \mathrm{C} ; 550 \mathrm{~h}$ at $40-50{ }^{\circ} \mathrm{C} ; 125 \mathrm{~h}$ at $60{ }^{\circ} \mathrm{C} ; 70 \mathrm{~h}$ at $70{ }^{\circ} \mathrm{C} ; 10 \mathrm{~h}$ at $80^{\circ} \mathrm{C} ; 7 \mathrm{~h}$ at $90{ }^{\circ} \mathrm{C}$ ). Arrhenius plots (Fig. 5) were drawn using Eq. (3a).

Activation energies $E_{\mathrm{a}}=96.6 \pm 2.4$ and $E_{\mathrm{a}}=98.3 \pm$ $3.1 \mathrm{~kJ} \mathrm{~mol}^{-1}$ were, respectively, obtained for the $\mathrm{Fe}+\mathrm{Ac}$

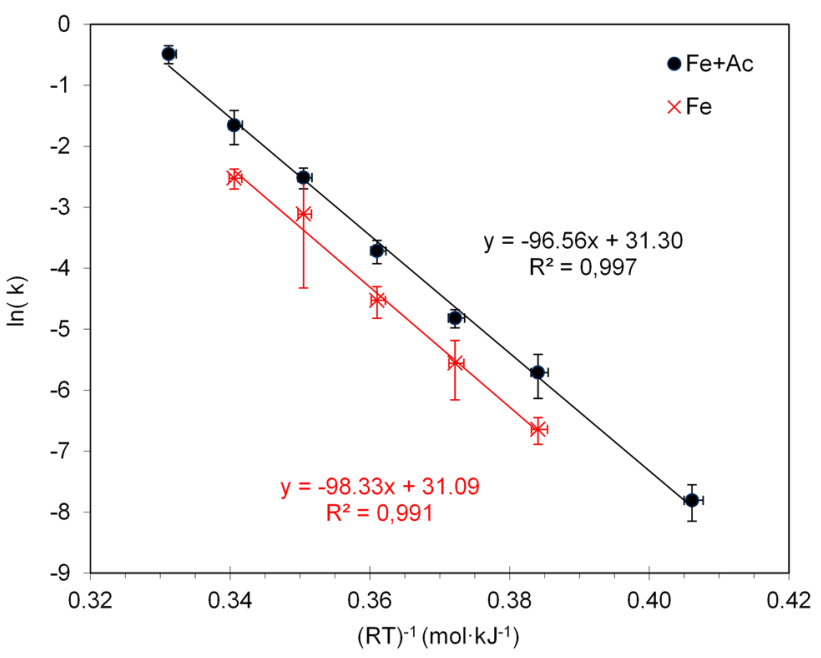

Fig. 5 Arrhenius plot of zero-span measurements. Samples $\mathrm{Fe}+\mathrm{Ac}$ (black filled circle); samples Fe (red times symbol)

and Fe samples. These values are similar to those obtained with DP measurements following the Ekenstam approach.

\section{Discussion}

\subsection{Oxidation versus hydrolysis?}

IGI are acidic. The solutions $\mathrm{Fe}$ and $\mathrm{Fe}+\mathrm{Ac}$ studied in this work have $\mathrm{pH}$ values 3.6 and 3.2, respectively 
(Table 2). As a result, papers impregnated with these inks are acidic with $\mathrm{pH}$ values 4.2 and 3.7 , respectively. Sulphuric acid is often put forward as the main cause of acidity [10], but this interpretation is not convincing: inks are not made with sulphuric acid, but with sulphate salts and released sulphate ions cannot account for low $\mathrm{pH}$ value of the ink that is more probably attributable to formation of iron(II)/iron(III) solvation complexes and to gallic acid dissociation $(\mathrm{pKa}=4.5)$. Anyway, whatever the cause of acidity, the low $\mathrm{pH}$ values of our samples give substantial reasons to suspect acid-catalysed hydrolysis as the main cause of chain scission.

This first interpretation does not stand when examining paper behaviour in further details: in previous work [26], ink impregnated papers were conditioned in anoxia and their degradation was delayed. Moreover, papers impregnated with pure gallic acid did not show significant depolymerization at ambient temperature despite showing a low $\mathrm{pH}$ value (3.6). Also $\mathrm{pH}$ is certainly an important factor, but it does not alone account for the depolymerization observed on ink impregnated papers.

On these papers, the most surprising aspect of the depolymerization lies in its rapidity that makes the phenomenon perceptible overnight. Here again, damages depend on environmental conditions: when wet samples are exposed overnight to high humidity conditions ( $>60 \%$ $\mathrm{RH}$ ), they still contain a significant amount of water (over $10 \% \mathrm{w} / \mathrm{w}$ ) (Fig. 1) and no significant variation of DP is observed (Fig. 2). Conversely, when these samples are exposed overnight to low humidity conditions $(<60 \%$ $\mathrm{RH})$, their drying is more advanced, they contain much less water (below $10 \%$ w/w) (Fig. 1), and the cellulose DP decreases by 10-20\% (Fig. 2). This behaviour suggests that reactive sites become accessible to oxygen in low humidity conditions, whereas they remain protected by water in high humidity conditions. It is consistent with a mechanism of depolymerization in which oxygen is a key factor.

One could think that the decrease in DP recalls the "initial rapid change in DP, before linear kinetics are established" [12] which corresponds to the juxtaposition of a fast and slow kinetic several times observed in the literature (Table 1, Daruwalla et al. [13], Rychly et al. [35]). This change has in the past been "attributed to rapid breaking of a small number of weak bonds" [12]. The concept of weak bonds (or weak links) is often questioned in the paper research community, most of the time driving scepticism. Zou et al. [14] did not find any experimental evidence of weak links on bleached kraft and bleached bisulphite pulps. Calvini [36] proposes to include the notion of weak bond in his kinetic model, but does not appear fully convinced by this notion as he mentions that "apparent weak link degradation can also be attributed to
[...] variation of the polydispersity index for specimens [papers] that do not follow the most probable distribution of Mw (e.g. [...] pulp with relatively high hemicellulose content)". Finally, Emsley, in his editorial on cellulose degradation [37, 38], clearly maintains not being in "favour of the concept of weak bonds" but prefers to "think in terms of a spectrum of reactivities".

Considering the above-mentioned literature, there is no objective reason to attribute the DP decrease observed on IGI impregnated papers to an eventual content of "weak links" as Whatman No 1 paper is one of the best linear cellulose models showing a Gaussian distribution of molar mass.

Our experiments show that the DP loss is directly linked to the presence of oxygen (and probably his accessibility to reactive sites). It is also related to the presence of iron(II) ions a significant proportion of which (20-30\%) is transformed to iron(III) during drying at $50 \% \mathrm{RH}$ [26]. This transformation implies reactive oxygen species that might have an impact on cellulose chain scissions.

\subsection{Discussing the reliability of artificial ageing experiments}

The Arrhenius plots obtained from DP measurements data between 23 and $90{ }^{\circ} \mathrm{C}$ (Figs. 4, 5) show an excellent linear correlation, with $R^{2}$ factors over 0.99 , providing experimental evidence of the reliability of the Arrhenius law to extrapolate to room temperature kinetic studies performed with artificial ageing. Interestingly, activation energies measured in this study, the average value of which is $97 \pm 2 \mathrm{~kJ} \mathrm{~mol}^{-1}$, are close to the value of $92 \mathrm{~kJ} \mathrm{~mol}^{-1}$ taken as an average of published activation energies by Reilly et al. [18] for evaluating the impact of temperature increase on short-lived organic materials.

This positive result should, however, be considered with great care for collection management purpose: the model samples of this study are designed to reproduce the main chemical degradation occurring on paper fibres that are in contact with ink, but they remain inappropriate to reproduce the decay of an original manuscript. Indeed on most original manuscripts, the ink is concentrated on top of the paper sheet (because of the initial paper size) and a few fibres only are concerned by the degradation that is reproduced on our samples. It should be kept in mind for collection management that the physical distribution of ink is the first key point of manuscript conservation. Paper degradation starts with humidity-driven migrations of iron in the sheet and around the ink line. The samples designed for this study do not model these migrations, because they are already fully impregnated with the ink. Moreover, the Arrhenius approach is not appropriate to model these phenomena that are mainly governed by physics and occur when the manuscript is exposed to high humidity 
conditions [39]. It has been shown, for instance, that these migrations become significant above $85 \% \mathrm{RH}$ even for a few hours of exposure [40, 41]. Keeping collections in dry environments remains the first precaution to be taken, long before speculating on temperature impact.

\subsection{DP measurements versus zero-span testing}

The data obtained in this work with zero-span and DP measurements lead to comparable values of activation energies, close to $97 \pm 2 \mathrm{~kJ} \mathrm{~mol}^{-1}$. This point may at first appear surprising, not to say suspicious when considering the numerous values of activation energies available in the literature, a small selection of which is reported in Table 1. It is, however, consistent with the fact that activation energy values measured with zero-span testing by Shahani et al. are similar to those found with DP measurements (Table 1, Shahani et al. [16]).

This coincidence finds a simple explanation: the first term $1 / \mathrm{DP}(t)-1 / \mathrm{DP}_{0}$ of the Ekenstam approach (Eq. 1) actually corresponds to the average number of broken bonds per anhydroglucose unit. It is intuitive to suppose that the loss of zero-span tensile strength is correlated with the number of broken bonds. This correlation is in fact linear at least for loss of zero-span breaking strength below $60 \%$ as shown by the re-computation of data published by Zou et al. [14] (Fig. 6) or by other literature data [17, 42]. Considering this linear behaviour, one should expect similar activation energies for zero-span and DP measurements.

These observations lead to a second conclusion: DP measurements make it possible to quantify the early stage of degradation, a stage for which zero-span testing is not sensitive. On the opposite zero-span testing enables the measurement of a more advanced stage of degradation for which DP is poorly discriminant. The fact that similar

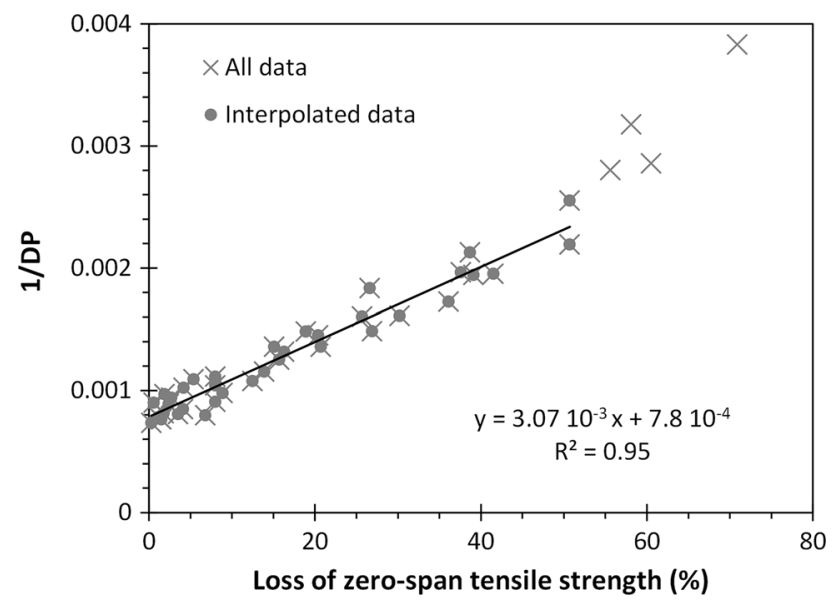

Fig. 6 Re-computation of zero-span tensile strength and DP data from Zou et al. [14] showing a linear correlation. Selection of some activation energy values related to paper degradation activation energies were found on DP and zero-span measurements proves that the mechanism of chain breaking remains unchanged all along the degradation.

\subsection{Discussing Activation energy values}

A large range of activation energy values have been proposed to model cellulose depolymerization, ranging from $55 \mathrm{~kJ} \mathrm{~mol}^{-1}$ [43] to $180 \mathrm{~kJ} \mathrm{~mol}^{-1}$ [44] depending on cellulosic materials and physical/chemical parameters taken to monitor degradation. Table 1 shows a selection of these activation energies that are believed to be the most relevant to this study.

As pointed out by Zou et al. [14], chain breaking may be produced by several reactions simultaneously occurring in the material, each of these at a different rate depending on reagent concentrations. In a limited range of temperature around a fixed value $T_{0}, \operatorname{Ln}(k)$ can be expressed in Taylor's series. The global activation energy appears then as a weighted average of activation energies of each independent reaction:

$E_{\mathrm{a}}=\frac{\sum_{i} E_{i} k_{i}^{0}}{\sum_{i} k_{i}^{0}}$

where $E_{\mathrm{i}}$ is the activation energy of reaction $i$ and $k_{i}^{0}$ its rate at $T_{0}$.

This point radically impairs interpretation of activation energies. It is, however, generally considered that higher activation energy values refer to pure acid-catalysed hydrolysis while lower values are correlated with oxidative mechanisms. These general considerations rely on several factors: first, activation energies measured in air condition are generally lower than those measured on similar samples but under nitrogen (Table 1, Shafizadeh et al. [11]); second, activation energies measured in dry environment (air without water) are lower than those measured in humid environment (Table 1, Kocar et al. [21]); third, low activation energies below $100 \mathrm{~kJ} \mathrm{~mol}^{-1}$ are measured by chemiluminescence, a technique sensitive to radical production (Table 1, Rychly et al. [35]); fourth, the decomposition of cellobiose in an oxidative Fenton reaction system leads to low activation energy of $55 \mathrm{~kJ} \mathrm{~mol}^{-1}$ (Table 1, Kwon et al. [43]); and fifth, high values of activation energy (in the range $127-179 \mathrm{~kJ} \mathrm{~mol}^{-1}$ ) are measured for cellulose hydrolysis in sulphuric acid solutions as reviewed by SriBala et al. [44] (see also Table 1, Kwon et al. [43]).

On IGI impregnated papers, intermediate values of activation energies (approx. $97 \pm 2 \mathrm{~kJ} \mathrm{~mol}^{-1}$ ) are measured, questioning a possible superimposition via Eq. (5) of two independent reactions, one corresponding to oxidative chain breaking (low $E_{\mathrm{a}}$ ) and the other to acidic hydrolysis (high $E_{\mathrm{a}}$ ). This scenario appears doubtful since reaction rates of IGI impregnated papers are between one and two 
orders of magnitude above those of blank papers. Indeed, reaction rates measured by Zou et al. [20] at $23{ }^{\circ} \mathrm{C}$ (natural ageing) on acidic papers ( $\mathrm{pH} 3.7)$ are around $4 \times 10^{-9} \mathrm{~h}^{-1}$ $\left(9.98 \times 10^{-8}\right.$ day $\left.^{-1}\right)$, a value, respectively, 70 and 30 times below reaction rates of $\mathrm{Fe}+\mathrm{Ac}$ and $\mathrm{Fe}$ samples at similar temperature. In these conditions, the weight of acidic hydrolysis terms in Eqs. (3a, 3b) is negligible, meaning that the measured activation energy corresponds to a dominant mechanism. It remains below but not far from the values found for pure acidic hydrolysis. This suggests a mechanism partly related to acidic hydrolysis, but with a catalytic effect of iron implying different reaction intermediates that lower the activation energy.

\section{Conclusion}

This work assesses the reliability of Arrhenius law for IGI chemical damage in temperature range $20-90{ }^{\circ} \mathrm{C}$. It confirms the possibility to extrapolate artificial ageing results to natural ageing conditions. This point is crucial for scientists involved in the chemical aspects of paper degradation. It should, however, be considered with great care by paper conservators and curators as the samples were designed to reproduce the chemical reactions occurring during paper decay by IGI but are not relevant to test the initial step of degradation occurring on original manuscripts, i.e. the migration of iron within the paper sheet because of humidity.

Our measurements show that the mechanism of chain breaking is driven by the combined impact of $\mathrm{pH}$, oxygen and iron. The activation energy of IGI impregnated paper depolymerization $\left(97 \pm 2 \mathrm{~kJ} \mathrm{~mol}^{-1}\right)$ is relatively close but inferior to activation energies measured on naturally aged lignin-free acidic papers $\left(109 \mathrm{~kJ} \mathrm{~mol}^{-1}\right)$. On the opposite, reaction rates of IGI impregnated papers are 1-2 orders of magnitude above those of lignin-free acidic papers. These observations are not consistent with the superimposition of two different pathways such as acidic hydrolysis and cellulose oxidation, but suggest a dominant hydrolytic process that involves directly or indirectly oxygen and iron.

Acknowledgments This work was supported by French state funds managed by the Ile de France Region (DIM Oxymore) and ANR within the "Investissements d'Avenir program" under reference ANR-11-IDEX-0004-02, and more specifically within the framework of the Cluster of Excellence MATISSE led by Sorbonne Universités.

\section{References}

1. J. Kolar, M. Strlic, (eds.), Iron Gall Inks: On Manufacture, Characterisation, Degradation and Stabilisation (National and University Library, Ljubljana. 2006)

2. J. Gust, J. Suwalski, Corrosion. 50, 355 (1994)
3. C. Krekel, Int. J. Forensic Doc. Exam. 5, 54 (1999)

4. C.H. Wunderlich, R. Weber, G. Bergerhoff, Zeitschrift für Anorganische und Allgemeine Chemie. 598/599, 371 (1991)

5. A. Kongdee, T. Bechtold, Cellulose 16, 53 (2009)

6. C. Burgaud, V. Rouchon, A. Wattiaux, J. Bleton, R. Sabot, P. Refait, J. Electroanal. Chem. 650, 16 (2010)

7. J.G. Neevel, Restaurator. 16, 143 (1995)

8. M. Strlic, J. Kolar, (eds.), Ageing and Stabilisation of Paper (National and University Library, Ljubljana. 2005)

9. P. Calvini, Cellulose 12, 445 (2005)

10. S. Zervos, in Cellulose: Structure and Properties, Derivatives and Industrial Uses, ed. by A. Lejeune and T. Deprez (Nova Science, 2010), p. 155-203

11. F. Shafizadeh, A.G.W. Bradbury, J. Appl. Polym. Sci. 23, 1431 (1979)

12. A.M. Emsley, G.C. Stevens, Cellulose 1, 26 (1994)

13. E.H. Daruwalla, M.G. Narsian, Tappi J. 49, 106 (1966)

14. X. Zou, T. Uesaka, N. Gurnagul, Cellulose 3, 243 (1996)

15. P.L. Bégin, E. Kaminska, Restaurator. 23, 89 (2002)

16. J. Shahani, S.B. Lee, F.H. Hengemihle, G. Harrison, P. Song, Accelerated Aging of Paper. I: Chemical Analysis of Degradation Products, II: Application of Arrhenius Relationship, III: Proposal for a new Accelerated Aging Test, ASTM research Program, Library of Congress, Washington, 2001

17. E. Kaminska, P. Bégin, D. Grattan, D. Woods, A. Bülow, Accelerated aging test method development for American Society for Testing and Materials Institute for Standards Research, ASTM Research Program, Canadian Conservation Institute, Otawa, 2001

18. J. M. Reilly, D. W. Nishimura, E. Zinn, New tools for preservation: assessing long-term environmental effects on library and archives collections (Commission of Preservation and Access, Washington, 1995), www.clir.org/pubs/reports/pub59/pub59.pdf. Accessed 15 July 2015

19. Standard BSI PAS 198 (2012)

20. X. Zou, T. Uesaka, N. Gurnagul, Cellulose 3, 269 (1996)

21. D. Kocar, M. Strlic, J. Kolar, J. Rychly, L. Matisova-Rychla, B. Pihlar, Polym. Degrad. Stabil. 88, 407 (2005)

22. M. Strilic, J. Kolar, (eds.), Ageing and Stabilisation of Paper (National and University Library, Ljubjana. 2005)

23. J. Kolar, A. Stolfa, M. Strilic, M. Pompe, B. Pihlar, M. Budnar, J. Simcic, B. Reissland, Anal. Chim. Acta. 555, (2006). doi:10. 1016/j.aca.2005.08.073

24. V.S. Selih, M. Strlic, J. Kolar, B. Pihlar, Polym. Degrad. Stabil. 92, 1476 (2007)

25. M. Strlic, J. Kolar, B. Pihlar, Polym. Degrad. Stabil. 73, 535 (2001)

26. V. Rouchon, M. Duranton, C. Burgaud, E. Pellizzi, B. Lavedrine, K. Janssens, W. de Nolf, G. Nuyts, F. Vanmeert, K. Hellemans, Anal. Chem. 83, 2589 (2011)

27. Standart ISO 535 (2014)

28. Standart ISO 17812 (2007)

29. Standard ISO 6588-1 (2005)

30. T. Sawoszczuk, A. Baranski, J.M. Lagan, T. Lojewski, K. Zieba, J. Cult. Herit. 9, 401 (2008)

31. Standart ISO 5351 (2010)

32. R. Evans, A.F.A. Wallis, in 4th International Symposium on Wood and Pulping Chemistry, Paris, Palais des Congrès, 27th30th April 1987 (1987)

33. J. Tetreault, A.L. Dupont, P. Begin, S. Paris, Polym. Degrad. Stabil. 98, 1827 (2013)

34. Standard TAPPI T $231 \mathrm{~cm}-96$ (1996)

35. J. Rychly, M. Strlic, L. Matisova-Rychla, J. Kolar, Polym. Degrad. Stabil. 78, 357 (2002)

36. P. Calvini, Cellulose 21, 1127 (2014)

37. A.M. Emsley, Cellulose 15, 187 (2008) 
38. A.M. Emsley, Cellulose 15, 239 (2008)

39. V. Rouchon, B. Durocher, E. Pellizzi, J. Stordiau-Pallot, Stud. Conserv. 54, 236 (2009)

40. V. Rouchon, M. Duranton, O. Belhadj, M. Bastier Desroches, V. Duplat, C. Walbert, B. Vinther Hansen, Polym. Degrad. Stabil. 98, 1339 (2013)

41. O. Belhadj, C. Phan Tan Luu, E. Jacobi, S. Meslet-Struyve, S. Vez, B. Reissland, V. Rouchon, J. Pap. Conserv. 15, 9 (2014)

42. A.L. Dupont, Le patrimoine culturel sur papier: de la compréhension des processus d'altération à la conception de procédés de stabilisation, Chemical Sciences, Evry Val d'Essonne University, 85 p. (2014) https://tel.archives-ouvertes.fr/tel01115774/document. Accessed 20th July 2015

43. Y. Kwon, S.E.F. Kleijn, K.J.P. Schouten, M.T.M. Koper, ChemSusChem. 5, 1935 (2012)

44. G. SriBala, R. Vinu, Ind. Eng. Chem. Res. 53, 8714 (2014) 